\title{
The Effectiveness of Online Learning for the Cognitive Domain of Course Learning Outcomes from the Students' Point of View
}

\author{
MUHAMMAD HUMAYUN ${ }^{1}$, AMBREEN KHALID ${ }^{2}$, ASMARA SYED ${ }^{3}$, EKRAMY ELMORSY ${ }^{3}$, ANAM ARSHAD ${ }^{1}$, MUHAMMAD $^{2}$ \\ DANIYAL HUMAYUN ${ }^{4}$, SYED SAJID HUSSAIN SHAH ${ }^{3}$ \\ ${ }^{1}$ Biochemistry Department, Central Park Medical College Lahore - Pakistan \\ ${ }^{2}$ Shalamar Medical and Dental College Lahore - Pakistan \\ ${ }^{3}$ Faculty of Medicine, Northern Border University, Arar- Kingdom of Saudi Arabia \\ ${ }^{4}$ Sharif Medical and Dental College, Lahore - Pakistan \\ Correspondence to Prof. Dr. Muhammad Humayun, E-Mail: mrhumayundr@gmail.com, Telephone : 00923328410180
}

\begin{abstract}
Aim: To explore the students' opinion about the learning of the cognitive domain of the course learning outcomes studied through online learning methodology.

Methods: A structured questionnaire containing eleven questions regarding the cognitive domain of course

learning outcomes has been distributed among the willing participants who are studying in the college of medicine. The completely filled questionnaires were evaluated.

Results: Two hundreds and one (201) completely filled questionnaire were received from the medical students which included one hundred and fifteen (115) female students $(57.2 \%)$ and 86 male students (42.8\%). The main benefits of the online learning in the opinion of the students are that the Online teaching enhanced their capability to search for the other available teaching material on the internet, helped them in learning independently and reduced their preparation time along with travelling fatigue. The opinion expressed by the students regarding the understanding of difficult concepts is that it is better in face to face classes as compared to online lecture.

Conclusion: The Online learning is an effective teaching technique in the current digital era but with some limitations as students feel difficulty in understanding the difficult concepts in medicine through online learning. Keywords: Online Learning, Cognitive Domain. Learning Outcome
\end{abstract}

\section{INTRODUCTION}

The effective learning of professional skills has got paramount importance in the development of an individual as well as in the entire community. There are three main domains which comprised the process of learning. These domains are cognitive, psychomotor and affective. The cognitive domain involves the process of learning associated with skill of thinking. The cognitive learning process is comprised six levels. These levels include knowledge, comprehension, application, analysis, synthesis and evaluation.

The first level of learning is knowledge in which the learner learns the definition of the terms. The comprehension is the second level of learning. In this level, the learner is able to work on the assigned task and example it. The student recognizes and applies the methods to find the solutions of the problem in the third level which is designated as Application. The fourth level of the cognitive domain is analysis, in which the learner is able to explain that why would the process of the solution worked. The synthesis is the fifth level of the cognitive domain, in which the learner is capable of combing the part of the process in a novel and effective way. The evaluation is the sixth level of the cognitive domain. At this stage, the learner is able to synthesize variety of ways for the solution of the problems and can select the appropriate method to resolve the issue ${ }^{1}$.

To achieve the excellence in the learning process, the application of effective strategies for the effective teaching and learning process may also play a vital role. One of the

Received on 03-04-2021

Accepted on 13-08-2021 important factor in the learning process is the teachers' qualities ${ }^{2}$. But multiple other factors also play an important role in the learning. The continuous assessment and evaluation of the different techniques and tool applied in the process of learning would lead to find out the additional ways and means for the improvement in this regards. In the evaluation of teaching strategies, a feedback from the learners may also provide very valuable information as the students are a very vital component of the teaching and learning process. The good feedback practices help in the improvement of teaching strategies ${ }^{3-4}$.

After the declaration of COVID- 19 as pandemic by the WHO in 2020, many activities related to human to human interaction were ceased which included the shutdown of institutions ${ }^{5}$. Due to this emergency situation, many institutions shifted to the online learning ${ }^{6}$. In medical institution, online teaching was started in order to reduce the exposure of undergraduate students of medicine to the coronavirus.

In the present scenario of COVID-19 pandemic, online learning tool is being practiced quite commonly all over the world. It would be appropriate to listen to the students' opinion regarding the online learning with respect to the cognitive domain of the course learning outcomes.

The main aim and objective of the present study is to find out the perception of students regarding the online learning particularly about the cognitive domain of the course learning outcomes.

\section{MATERIALS AND METHODS}

The research project has been submitted to the institutional research ethical committee and after the approval, the questionnaire has been distributed among the willing 
students who are studying in $1^{\text {st }} \& 2^{\text {nd }}$ year in the Central Park Medical College, Lahore - Pakistan. The structured pro-forma contained eleven questions. The survey was conducted during the month of August 2021. The proforma did not include any questions related to the personal identification such as name, phone number and Email address. No identification of the any participant can be traced from the collected data. The completely filled questionnaires were included for the data analysis.

\section{RESULTS}

A total of Two hundreds and one (201) willing participants who are students of academic phase (1st year \& $2^{\text {nd }}$ year) in the Central Park Medical College, Lahore - Pakistan had participated in the study. There were one hundred and fifteen (105) female students (57.2\%) and 86 male students $(42.8 \%)$. Majority of the students have the opinion that the online teaching enhanced their capability to search for the other available teaching material on the internet and helped them in learning independently. Most of the students think that the online teaching reduced their preparation time (changing clothes / shoes etc.) and travelling fatigue which helped them in increasing their study time. A significant number of students disagree the notion that the understanding of difficult concepts is better in online lecture as compared to actual classroom teaching. Similarly the majority of students do not think that the online teaching enhanced their thinking ability and improved their examination scores. The results have been shown in the table

Table: The perception of medical students regarding online learning

\begin{tabular}{|c|c|c|c|c|c|c|c|c|c|c|c|c|c|c|c|}
\hline \multirow[t]{2}{*}{ Question } & \multirow[t]{2}{*}{$\begin{array}{l}\stackrel{Q}{\Phi} \\
\frac{\Phi}{0} \\
\frac{0}{\Phi}\end{array}$} & \multirow[t]{2}{*}{ 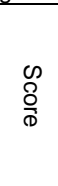 } & \multicolumn{2}{|r|}{ 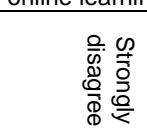 } & \multicolumn{2}{|r|}{ 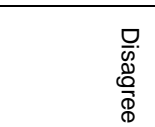 } & \multicolumn{2}{|r|}{ 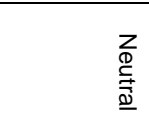 } & \multicolumn{2}{|r|}{ 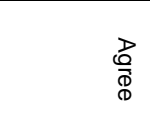 } & \multicolumn{2}{|r|}{ 㞔 } & \multicolumn{2}{|r|}{$\begin{array}{l}\text { 몸 } \\
\stackrel{\underline{\underline{D}}}{2}\end{array}$} & \multirow[t]{2}{*}{ 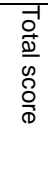 } \\
\hline & & & $z$ & $\circ$ & & $\circ$ & & $\circ^{\circ}$ & $J$ & $\circ$ & $z$ & $\circ$ & & $\circ^{\circ}$ & \\
\hline \multirow{2}{*}{$\begin{array}{l}\text { Understanding of difficult } \\
\text { concepts is better in online } \\
\text { lecture as compared actual } \\
\text { classroom }\end{array}$} & $F$ & 2.1 & 41 & 35.65 & 39 & 33.91 & 22 & 19.13 & 8 & 6.96 & 5 & 4.35 & 115 & 100 & \\
\hline & $M$ & 2.0 & 41 & 47.67 & 18 & 20.93 & 14 & 16.28 & 8 & 9.30 & 5 & 5.81 & 86 & 100 & \\
\hline \multirow{2}{*}{$\begin{array}{l}\text { Sitting alone on computer and } \\
\text { listening to the Lecture improves } \\
\text { my concentration in the lecture }\end{array}$} & $\mathrm{F}$ & 3.0 & 15 & 13.04 & 30 & 26.09 & 28 & 24.35 & 26 & 22.61 & 17 & 14.78 & 116 & 101 & \multirow[t]{2}{*}{3.2} \\
\hline & $\mathrm{M}$ & 2.8 & 18 & 20.93 & 18 & 20.93 & 21 & 24.42 & 19 & 2.09 & 10 & 11.63 & 86 & 100 & \\
\hline \multirow{2}{*}{$\begin{array}{l}\text { Sitting alone on computer and } \\
\text { listening to the Lecture decreases } \\
\text { my nervousness as compared to } \\
\text { the physical presence in the } \\
\text { classroom }\end{array}$} & $\mathrm{F}$ & 3.2 & 17 & 14.78 & 19 & 16.52 & 24 & 20.87 & 35 & 30.43 & 20 & 17.39 & 115 & 100 & \multirow[b]{2}{*}{3.3} \\
\hline & $M$ & 3.5 & 9 & 10.47 & 12 & 13.95 & 13 & 15.12 & 34 & 39.53 & 18 & 20.93 & 86 & 100 & \\
\hline \multirow{2}{*}{$\begin{array}{l}\text { Online teaching reduces my } \\
\text { preparation time (changing } \\
\text { clothes / shoes etc.) }\end{array}$} & $F$ & 3.7 & 6 & 5.22 & 13 & 11.30 & 18 & 15.65 & 55 & 47.83 & 23 & 20.00 & 115 & 100 & \multirow[b]{2}{*}{3.6} \\
\hline & $M$ & 3.7 & 6 & 6.98 & 8 & 9.30 & 13 & 15.12 & 36 & 41.86 & 23 & 26.74 & 86 & 100 & \\
\hline \multirow{2}{*}{$\begin{array}{l}\text { Online lectures reduces my } \\
\text { travelling fatigue which helps in } \\
\text { increasing my study time }\end{array}$} & $F$ & 3.6 & 7 & 6.09 & 14 & 12.17 & 27 & 23.48 & 42 & 36.52 & 25 & 21.74 & 115 & 100 & \multirow[b]{2}{*}{3.6} \\
\hline & $M$ & 3.7 & 8 & 9.30 & 10 & 11.63 & 9 & 10.47 & 33 & 38.37 & 26 & 30.23 & 86 & 100 & \\
\hline \multirow{2}{*}{$\begin{array}{l}\text { Online class reduces my fear in } \\
\text { asking the questions as } \\
\text { compared to the physical } \\
\text { presence in the classroom. }\end{array}$} & $\mathrm{F}$ & 3.0 & 14 & 12.17 & 27 & 23.48 & 31 & 26.96 & 26 & 22.61 & 17 & 14.78 & 115 & 100 & \multirow{2}{*}{3.1} \\
\hline & $M$ & 3.0 & 12 & 13.95 & 15 & 17.44 & 30 & 34.88 & 16 & 18.60 & 13 & 15.12 & 86 & 100 & \\
\hline \multirow{2}{*}{$\begin{array}{l}\text { Online teaching has improved my } \\
\text { computer skills }\end{array}$} & $F$ & 3.2 & 11 & 9.57 & 13 & 11.30 & 43 & 37.39 & 34 & 29.57 & 14 & 12.17 & 115 & 100 & \multirow{2}{*}{3.2} \\
\hline & $M$ & 3 & 12 & 13.95 & 18 & 20.93 & 2 & 26.74 & 2 & 27.91 & 9 & 10.47 & 86 & 100 & \\
\hline \multirow{2}{*}{$\begin{array}{l}\text { Online teaching enhanced my } \\
\text { capability to search for the other } \\
\text { available teaching material on the } \\
\text { internet }\end{array}$} & $\mathrm{F}$ & 3.9 & 2 & 1.74 & 9 & 7.8 & & & & 49.57 & 29 & 25.22 & 115 & 100 & \multirow[b]{2}{*}{3.9} \\
\hline & $M$ & 3.6 & 7 & 8.14 & 9 & 10.47 & 17 & 19.77 & 35 & 40.70 & 18 & 20.93 & 86 & 100 & \\
\hline \multirow{2}{*}{$\begin{array}{l}\text { Online teaching improved my } \\
\text { exam. scores }\end{array}$} & $F$ & 2.5 & 16 & 13.91 & 42 & 36.52 & 4 & 34.78 & 1 & 11.30 & 4 & 3.48 & 115 & 100 & \multirow{2}{*}{2.6} \\
\hline & $M$ & 2.9 & 18 & 20.93 & 17 & 19.77 & 2 & 23.26 & 2 & 23.26 & 11 & 12.79 & 86 & 100 & \\
\hline \multirow{2}{*}{$\begin{array}{l}\text { Online lectures enhanced my } \\
\text { thinking ability. }\end{array}$} & $\mathrm{F}$ & 2.7 & 16 & 13.91 & 32 & 27.83 & 41 & 35.65 & 20 & 17.39 & 6 & 5.22 & 115 & 100 & \multirow{2}{*}{2.7} \\
\hline & $M$ & 2.6 & 16 & 18.60 & 27 & 31.40 & 26 & 25.58 & 14 & 16.28 & t & 8.14 & 86 & 100 & \\
\hline Online lectures helped me & $\mathrm{F}$ & 3.4 & 9 & 7.83 & 20 & 17.39 & 27 & 23.48 & 38 & 33.04 & 21 & 18.26 & 115 & 100 & \\
\hline learning independently & $\mathrm{M}$ & 3.5 & 9 & 10.47 & 12 & 13.95 & 12 & 13.95 & 35 & 40.70 & 18 & 20.93 & 86 & 100 & \\
\hline
\end{tabular}

\section{DISCUSSION}

In the present study, according to the students' point of view, the online learning has improved their capability to explore for the availability of teaching material on the internet. The majority of students also expressed the impression that the online teaching has helped them in learning independently. A significant number of students think that online teaching reduced their preparation time and travelling fatigue.

The saving of the travelling time and provision of the flexibility has been reported as main advantage of the online teaching in a large study in which students from 39 UK medical school participated?.

The study conducted in Poland regarding the perception of medical students about online learning revealed that the majority of the students think the key advantage of the online learning is staying at home with continuous availability of online course material. While absence of patient interaction and technical issues of the information technology were the limiting factors of the online learning in this study ${ }^{8}$. 
In the present study, most of the students think that the understanding of difficult concepts is better in actual classroom (face to face) as compared to online lecturing which is contrary to the finding of the study conducted by Bączek $\mathrm{M}$ et al, in which they do not find any statistical difference in the students opinion regarding the gaining of knowledge in face to face verses online teaching ${ }^{8}$.

In another study, most of the students expressed their positive opinion about the use of online teaching as an alternative to the classical teaching method in the period of COVID -19 pandemic and students found electronic learning more interactive ${ }^{9}$.

A study published by Uma $G$ et al revealed that majority of the students (55.7\%) prefer online learning over face to face teaching ${ }^{10}$.

With the advancement in the digital communication, the distant learning has become quite possible. The e learning or electronic couching may yield healthy impact on the process of medical education ${ }^{11}$. A study published by Waseem $T$ et al revealed that a significant number of students think that the use of social networking sites has facilitated them in the conceptual understanding ${ }^{12}$.

The continuous evaluation of the teaching methods and techniques in the light of the learners' feedback has got vital importance for the further improvement of current methods as well as for the development of new strategies. Further studies regarding the students' and teachers' perception about the psychomotor and effector domains of learning by online teaching method are suggested along with the challenges faced by them during the process of online learning and teaching.

Acknowledgement: The authors are thankful to Jannat Zaib Mir and Mohtashim Dar for their assistance.

\section{Conflict of interest: None}

\section{Funding: None}

\section{REFERENCES}

1. Hoque ME. Three Domains of Learning: Cognitive, Affective and Psychomotor. The Journal of EFL Education and Research. 2016: 2(2);45-52

2. Syed Sajid Hussain Shah. The Assessment of Students' Perception Regarding the Qualities of Teacher which
Influence their Learning Process. P J M H S. 2019:13(3);724727

3. Mamoon-Al-Bashir M, Kabir MR, Rahman I. The Value and Effectiveness of Feedback in Improving Students' Learning and Professionalizing Teaching in Higher Education. Journal of Education and Practice. 2016;7(16);38-41

4. Minnoni E, Tomei N, Collini M. The Value of Feedback in the Learning Process, Teaching and Learning Together in Higher Education: Iss. 20 (2017), http://repository.brynmawr.edu/tlthe/vol1/iss20/8

5. Adedoyin OB, Soykan E. Covid-19 pandemic and online learning: the challenges and opportunities. Interactive Learning 2020.2 DOI: 10.1080/10494820.2020.1813180

6. Conlon TA, Mc Carthy P, Mc Govern R, Slattery S, Yates J, Murphy S. The Impact of Covid-19 on Medical Student Education - Navigating Uncharted Territory. Ir Med J. 2020 ;113 (6); 109.

7. Dost S, Hossain A, Shehab M, Abdelwahed A, Al-Nusair L. Perceptions of medical students towards online teaching during the COVID-19 pandemic: a national cross-sectional survey of 2721 UK medical students. BMJ Open 2020;10:e042378. doi:10.1136/ bmjopen-2020-042378

8. Bączek M, Zagańczyk-Bączek M, Szpringer M, Jaroszyński A, Wożakowska-Kapłon B. Students' perception of online learning during the COVID-19 pandemic: a survey study of Polish medical students. Medicine. 2021;100:7(e24821). doi: 10.1097/MD.0000000000024821

9. Ibrahim NK, Al-Raddadi R, Al-Darmasi M, Al-Ghamdi A, Gaddoury M, Hussain M. et al. Medical students' acceptance and perceptions of e-learning during the Covid-19 closure time in King Abdulaziz University, Jeddah. Journal of Infection and Public Health. 2021;14(1);17-23, https://doi.org/10.1016/j.jiph.2020.11.007.

10. Uma G, Vartika T, Kumar GN. Perception about online learning among medical students in northern India during lockdown period of COVID - 19: a cross sectional study. International Journal of Contemporary Medical Research. 2020;7(12):L6-L10

DOI:http://dx.doi.org/10.21276/ijcmr.2020.7.12.17

11. Tariq FJ. E-Coaching trends in Medical teaching. $\mathrm{P} J \mathrm{M} \mathrm{H} \mathrm{S}$. 2019;13(4); 716

12. Waseem T, Ashraf MH, Rabbani S, Shoaib H, Khan RA. Evolving Role of Social Networking Sites in Undergraduate Surgical Education: Student Perspective. P J M H S. 2019;13(4); 894-899 